\title{
Acceptance of universal varicella vaccination among Swiss pediatricians and general practitioners who treat pediatric patients
}

Florian Lienert ${ }^{1,2^{*}}$, Olivia Weiss ${ }^{3}$, Kathrin Schmitt ${ }^{3}$, Ulrich Heininger ${ }^{4}$ and Patrik Guggisberg ${ }^{1}$

\begin{abstract}
Background: Over the last two decades, several countries have initiated universal varicella vaccination (UW) programs in infants. In 2019, the Swiss National Immunization Technical Advisory Group (NITAG) decided to start evaluating the introduction of universal varicella vaccination. There is a theoretical concern that suboptimal vaccination coverage could lead to a shift in the varicella incidence to older age groups, thereby potentially increasing complication rates. To achieve a high vaccination coverage rate, it is important that practicing physicians comply with a potential recommendation for UW.

We studied the perception of varicella and the current vaccination behavior among Swiss pediatricians and general practitioners (GPs) who treat children. We also assessed their intention to advise parents to vaccinate their children against varicella in the event the Swiss NITAG will recommend UW.
\end{abstract}

Methods: Primary data was collected through a structured, 20-min online survey with Swiss pediatricians and GPS who treat children.

Results: 150 physicians participated in the study: 40 GPs in the German-speaking part, 20 GPs in the Frenchspeaking part, 67 pediatricians in the German-speaking part, and 23 pediatricians in the French-speaking part. The majority (64\%) of all participants reported that they currently recommend varicella vaccination for risk groups according to the national immunization plan. About one third of physicians (35\%) - predominantly pediatricians currently already recommend it for all infants. In these situations, a measles, mumps, rubella, varicella combination vaccine is currently used by 58\% for the first dose and by 59\% for the second dose.

$86 \%$ of participants stated that they would advise parents to have their children vaccinated against varicella in case of a recommendation for UW by the Swiss NITAG. 68\% responded that they expect many questions from parents and $65 \%$ agreed that they have good arguments to convey the importance of varicella vaccination.

(Continued on next page)

\footnotetext{
*Correspondence: florian.lienert@gmail.com

${ }^{1}$ MSD Merck Sharp \& Dohme AG, Lucerne, Switzerland

${ }^{2}$ Current affiliation: Bavarian Nordic AG, Zug, Switzerland

Full list of author information is available at the end of the article
}

\section{$\triangle B M C$}

(c) The Author(s). 2020 Open Access This article is licensed under a Creative Commons Attribution 4.0 International License, which permits use, sharing, adaptation, distribution and reproduction in any medium or format, as long as you give appropriate credit to the original author(s) and the source, provide a link to the Creative Commons licence, and indicate if changes were made. The images or other third party material in this article are included in the article's Creative Commons licence, unless indicated otherwise in a credit line to the material. If material is not included in the article's Creative Commons licence and your intended use is not permitted by statutory regulation or exceeds the permitted use, you will need to obtain permission directly from the copyright holder. To view a copy of this licence, visit http://creativecommons.org/licenses/by/4.0/ The Creative Commons Public Domain Dedication waiver (http://creativecommons.org/publicdomain/zero/1.0/) applies to the data made available in this article, unless otherwise stated in a credit line to the data. 
(Continued from previous page)

Conclusions: The survey study results show that most participating pediatricians and GPs indicated a favorable attitude towards childhood vaccination against varicella in the setting of a Swiss NITAG recommendation for UW. This data shows the importance of NITAG recommendations in influencing vaccine education and supporting achievement of high coverage of varicella vaccination.

Keywords: Varicella zoster virus, Varicella, Chickenpox, Vaccination, Survey, GP, Pediatricians, Switzerland

\section{Background}

Varicella is a common infectious disease that is caused by varicella zoster virus (VZV), which is transmitted from humans to humans by droplets [1, 2]. Varicella is typically a mild disease but can cause serious complications; the rate for complications in children and adolescents in Switzerland has been estimated at 1 hospitalization per 1000 varicella cases [3]. In adults the hospitalization rate is up to 10-fold higher [2].

In Switzerland, vaccinations are voluntary; the decision to vaccinate oneself and one's children is each individual's responsibility. An annual vaccination schedule serves as a national guideline and classifies recommended vaccinations as either "basic", "supplementary", or "risk-based" vaccinations. Vaccinations are defined as "basic" if considered essential for individual and public health. These must be recommended by physicians to their patients. Vaccinations that provide optimal individual protection and are intended for people who want to protect themselves against clearly defined risks, but are not considered essential for public health, are categorized as "supplementary". Physicians in Switzerland must inform their patients of the existence of supplementary vaccinations. Universal vaccination against varicella during childhood is not recommended. The Swiss Federal Office of Public Health currently recommends varicella vaccination in individuals 11 to 40 years of age who have not contracted varicella naturally in the past (i.e. who do not have a reliable varicella history or are seronegative for VZV-IgG serum antibodies) as a "basic" vaccination. Immunization against varicella is also recommended as a "risk-based" vaccination for individuals from the age of 1 year onwards with an increased risk for complications or transmission [4]. As in most other European countries at a time before implementation of universal varicella vaccination, over $90 \%$ of the Swiss population has had varicella by the age of 15 years [5].

The United States of America was the first country to introduce a UVV program, starting with a 1-dose recommendation in 1995 and switching to a 2-dose recommendation in 2005. UVV has also been introduced in Germany as a 1-dose program in 2004 with a switch to a 2 -dose program in 2009. In both countries, implementation of UVV resulted in a strong decline of the incidence of varicella and varicella-related hospitalizations and deaths [6, 7]. Italy started to progressively introduce UVV in different regions from 2003 on and switched to a national recommendation in 2017. Similarly, Spain progressed from UVV in a few regions to a national program in 2016 [8]. In both Italy and Spain, a progressive reduction in the incidence of cases and hospitalizations was found in regions that introduced varicella vaccination programs $[9,10]$. While several countries have universal varicella vaccination programs in place, many postponed their introduction due to concerns about a shift in the disease to older groups, an increase in herpes zoster in the elderly, and cost-effectiveness [11]. The concern about an age shift is based on modelling studies that suggested a high vaccination coverage $(>80 \%)$ is needed to prevent an increasing incidence rate of complications due to the potentially resulting shift in the incidence to older ages groups [12, 13].

In Switzerland, there is no legal basis for mandatory vaccinations except for situations of major epidemics. Thus, mandatory vaccination is not a means to ensure a high level of varicella vaccination. To achieve a high varicella vaccination coverage rate, it is however important that practicing physicians comply with a potential recommendation for UVV. In this study, we therefore aimed at determining the perception of varicella and the current vaccination behavior among Swiss pediatricians and GPs who treat children. We also wanted to assess their intention to advise parents to vaccinate their children against varicella in the event the Swiss NITAG will recommend UVV.

\section{Methods \\ Study population and design}

Participants were recruited by QualiPro (https://qualipro.ch/index.html), an agency specialized in Swiss healthcare professional recruitment for surveys, from their existing database. Based on screening questions, only office-based physicians from the German- and the French-speaking parts of Switzerland were selected. To qualify for participation, physicians had to be practicing in their specialty between 2 and 35 years and currently vaccinating children.

Based on previous experiences with unpublished surveys among physicians in Switzerland, a sample size of 130150 is achievable in terms of recruitment and has proven 
to provide robust results. Therefore, the following set of sample quotas was defined: 35-50 GPs in the Germanspeaking part, 15-20 GPs in the French-speaking part, 60-75 pediatricians in the German-speaking part, and 20-25 pediatricians in the French-speaking part. Once 150 participants responded, the recruitment was stopped.

In November 2019, 1'208 GPs and 1'054 pediatricians received an invite to participate in an online-based survey study. Reminders were sent one week later. The first 150 physicians who completed the screening questions and passed the screening criteria continued with the questionnaire. Once 150 eligible physicians completed the questionnaire, the link showed a quota full screen indicating that the survey has been closed and the link to the questionnaire was no longer active. Physicians who participated gave their informed consent by filling out the questionnaire.

The questionnaire (additional file 1) was similar to that used by other investigators on the same topic [14] and was adapted by the authors of this publication. It contained questions on background characteristics, knowledge about varicella, attitude towards universal varicella vaccination, and beliefs about the disease varicella and varicella vaccination. Most questions were phrased as statements on which the level of agreement was measured using a 5-point Likert scale.

\section{Data analysis}

\section{Attitude towards universal varicella vaccination}

The primary outcome of the study was to understand physicians' intention to advise parents to vaccinate their children against varicella in case the Swiss NITAG would recommend UVV. The respondents were asked to indicate on a 5-point Likert-scale whether they agreed with the following statement $(1=$ strongly disagree, $5=$ strongly agree): "If the NITAG recommends varicella vaccination for all infants starting at the age of $9(-12)$ months as a basic vaccination, I will advise parents to vaccinate their children against varicella". The respondents were classified to have a positive attitude towards a recommendation if they selected 4 or 5 on the 5 -point Likert-scale.

\section{Determinants of attitude towards universal varicella vaccination}

Knowledge about varicella:

We calculated a knowledge score that was based on six knowledge questions. The maximum of this score was 6 points ( 1 point per correct answer, see also additional file 1). Respondents were classified as having 'limited knowledge' ( $0-2$ points), 'moderate knowledge' (3-4 points) or 'good knowledge' (5-6 points) about varicella. We tested differences in knowledge between physicians using Pearson's $\mathrm{X}^{2}$ or Fisher's exact test. We applied the
Benjamini-Hochberg method with a false discovery rate of 0.05 to correct for multiple testing $[14,15]$.

Beliefs about varicella and varicella vaccination:

To get insight into the perceived severity of varicella, participating physicians were asked to assess the importance of vaccination for children (from the approved age onwards) for different vaccine-preventable diseases including varicella. General beliefs and perceptions about varicella and varicella vaccination were measured by 7 statements: "Varicella can cause serious complications", "Varicella generally has a mild disease course in healthy children", "I believe that varicella is a burden to working parents and causes productivity loss", "I think that varicella is a disease serious enough to vaccinate against", "Varicella is a disease one should have experienced as a child (in order to develop specific immunity)", "One should not keep children with varicella away from school or child care", and "I am worried about potential side effects of the varicella vaccination".

To study differences in beliefs between GPs and pediatricians mean scores and associated simultaneous Bonferroni confidence intervals with overall coverage of at least $95 \%$ were calculated.

Logistic regression analyses:

Logistic regression models were used to identify determinants for Swiss physicians' intention to advise parents to vaccinate their children against varicella in case of recommendation for UVV through the Swiss NITAG.

The following potential determinants were included in the univariable and multivariable logistic regression analyses: gender, years of practice, specialty, varicella knowledge score and beliefs about varicella and varicella vaccination (see additional file 1 for more details on included questionnaire items). Only significant variables were kept in the model.

For these regression analyses, the agreement on statements regarding beliefs about varicella and varicella vaccination was divided into three categories: a) no agreement ('strongly disagree' or 'disagree'), b) neutral ('neutral'), and c) agreement ('agree' or 'strongly agree'). A determinant was considered statistically significantly associated with the outcome if the $P$ value was $<0.05$. The logistic regression analyses were conducted using SPSS 24.0.

\section{Results}

\section{Response and background characteristics}

150 physicians participated in the study: 40 GPs in the German-speaking part, 20 GPs in the French-speaking part, 67 pediatricians in the German-speaking part, and 23 pediatricians in the French-speaking part. Their background characteristics are presented in Table 1. Overall, respondents included an equal number of male and female physicians. A large proportion had children of their 
Table 1 Background characteristics of participating physicians

\begin{tabular}{|c|c|c|c|c|c|c|}
\hline \multirow[b]{2}{*}{ Background characteristics } & \multicolumn{2}{|c|}{ Pediatricians $(N=90)$} & \multicolumn{2}{|c|}{ GPs $(N=60)$} & \multicolumn{2}{|c|}{ Total $(N=150)$} \\
\hline & $\mathrm{N}$ & $\begin{array}{l}\% \\
{[95 \% \mathrm{Cl}]}\end{array}$ & $\bar{N}$ & $\begin{array}{l}\% \\
{[95 \% \mathrm{Cl}]}\end{array}$ & $\mathrm{N}$ & $\%$ \\
\hline \multicolumn{7}{|l|}{ Region } \\
\hline German-speaking region of Switzerland & 67 & $74.0 \%[65.4-83.5]$ & 40 & $67.0 \%[54.7-78.6]$ & 107 & $71.0 \%$ \\
\hline French-speaking region of Switzerland & 23 & $26.0 \%[16.5-34.6]$ & 20 & $33.0 \%$ [21.4-45.3] & 43 & $29.0 \%$ \\
\hline \multicolumn{7}{|l|}{ Sex } \\
\hline Male & 34 & $37.8 \%[27.8-47.8]^{*}$ & 43 & $71.7 \%[60.3-83.1]^{*}$ & 77 & $51.0 \%$ \\
\hline Female & 56 & $62.2 \%[52.2-72.2]^{*}$ & 17 & $28.3 \%[16.9-39.7]^{*}$ & 73 & $49.0 \%$ \\
\hline \multicolumn{7}{|l|}{ Years in Practice } \\
\hline $2-10$ years & 26 & $28.9 \%$ [19.5-38.3] & 17 & $28.3 \%$ [16.9-39.7] & 43 & $28.7 \%$ \\
\hline $11-20$ years & 47 & $52.2 \%$ [41.9-62.5] & 26 & $43.3 \%$ [30.8-55.9] & 73 & $48.7 \%$ \\
\hline $21-35$ years & 17 & $18.9 \%[10.8-26.9]$ & 17 & $28 \%[16.9-39.7]$ & 34 & $22.7 \%$ \\
\hline \multicolumn{7}{|l|}{ Have children on their own } \\
\hline Yes & 75 & $83.0 \%$ [75.6-91.0] & 52 & $87.0 \%$ [78.1-95.3] & 127 & $84.7 \%$ \\
\hline No & 15 & $17.0 \%[8.9-24.4]$ & 8 & $13.0 \%[4.7-21.9]$ & 23 & $15.3 \%$ \\
\hline \multicolumn{7}{|c|}{ Have their children fully vaccinated as per NIP } \\
\hline Yes & 75 & $100.0 \%[100 \%]$ & 52 & $100.0 \%[100 \%]$ & 127 & $100.0 \%$ \\
\hline No & 0 & $0 \%$ & $0 \%$ & $0 \%$ & 0 & $0 \%$ \\
\hline
\end{tabular}

* significant difference between GPs and pediatricians ( $p$-value $<0.05)$

own and all of them reported complete immunization of their own children according to the National Immunization Plan (NIP).

\section{Attitude towards universal varicella vaccination}

Most physicians reported their intention to advise parents to vaccinate their children against varicella if universal varicella vaccination was recommended by the Swiss NITAG as a basic vaccination (Table 2).
Interestingly, 92\% of pediatricians reported intention to comply with universal varicella vaccination, while the proportion among GPs was $77 \%$.

A smaller proportion of respondents had the intention to advise parents to vaccinate their children against varicella if universal varicella vaccination was recommended by the Swiss NITAG as a supplementary vaccination rather than as a basic vaccination ( $73 \%$ vs $86 \%, p=0.05)$. Most physicians (78\%) agreed that a NITAG recommendation to use a measles, mumps, rubella, varicella

Table 2 Perception and attitudes about a universal varicella vaccination

\begin{tabular}{|c|c|c|c|c|c|c|}
\hline \multirow[b]{2}{*}{ Questionnaire Item } & \multicolumn{2}{|c|}{$\begin{array}{l}\text { Pediatricians } \\
(\mathrm{N}=90)\end{array}$} & \multicolumn{2}{|c|}{ GPs $(N=60)$} & \multicolumn{2}{|c|}{$\begin{array}{l}\text { Total }(\mathrm{N}= \\
150)\end{array}$} \\
\hline & $\bar{N}$ & $\begin{array}{l}\%^{\mathrm{a}} \\
{[95 \% \mathrm{Cl}]}\end{array}$ & $\overline{\mathrm{N}}$ & $\begin{array}{l}\%^{\mathrm{a}} \\
{[95 \% \mathrm{Cl}]}\end{array}$ & $\overline{\mathrm{N}}$ & $\%^{a}$ \\
\hline $\begin{array}{l}\text { If the NITAG recommends varicella vaccination for all infants starting at the age of } 9(-12) \text { months as a } \\
\text { basic vaccination, I will advise parents to vaccinate their children against varicella }\end{array}$ & 83 & $\begin{array}{l}92.2 \% \\
{[86.7-97.8]^{*}}\end{array}$ & 46 & $\begin{array}{l}76.7 \% \\
{[65.9-87.4]^{*}}\end{array}$ & 129 & $86.0 \%$ \\
\hline $\begin{array}{l}\text { A strong recommendation from the NITAG to use the quadrivalent measles, mumps, rubella, varicella } \\
\text { (MMRV) will lead to higher vaccination rates }\end{array}$ & 74 & $\begin{array}{l}82.2 \% \\
{[74.3-90.1]}\end{array}$ & 43 & $\begin{array}{l}71.7 \% \\
{[60.3-83.1]}\end{array}$ & 117 & $78.0 \%$ \\
\hline $\begin{array}{l}\text { If the NITAG recommends varicella vaccination for all infants starting at the age of 9 (-12) months as a } \\
\text { supplementary vaccination, I will advise parents to vaccinate their children against varicella }\end{array}$ & 73 & $\begin{array}{l}81.1 \% \\
{[73.0-89.2]^{*}}\end{array}$ & 36 & $\begin{array}{l}60.0 \% \\
{[47.6-72.4]^{*}}\end{array}$ & 109 & $72.7 \%$ \\
\hline I expect many questions from parents about varicella vaccination should it be recommended universally & 60 & $\begin{array}{l}66.7 \% \\
{[56.9-76.4]}\end{array}$ & 41 & $\begin{array}{l}68.3 \% \\
{[56.6-80.1]}\end{array}$ & 101 & $67.3 \%$ \\
\hline I have good arguments to convince parents of the importance of vaccination against varicella & 68 & $\begin{array}{l}75.6 \% \\
{[66.7-84.4]^{*}}\end{array}$ & 30 & $\begin{array}{l}50.0 \% \\
{[37.4-62.7]^{*}}\end{array}$ & 98 & $65.3 \%$ \\
\hline $\begin{array}{l}\text { It will be difficult to discuss with parents about varicella vaccination should it be recommended } \\
\text { generally }\end{array}$ & 25 & $\begin{array}{l}27.8 \% \\
{[18.5-37.0]}\end{array}$ & 19 & $\begin{array}{l}31.7 \% \\
{[19.9-43.4]}\end{array}$ & 44 & $29.3 \%$ \\
\hline
\end{tabular}

${ }^{\mathrm{a}}$ Top 2 Box $(4+5)$ on 5 -point scale $(1=$ strongly disagree, 5 = strongly agree $){ }^{*}$ significant difference between GPs and pediatricians $(p-v a l u e ~<0.05)$ 
combination vaccine (MMRV) will lead to higher vaccination rates.

Most respondents expect many questions from parents about varicella vaccination should it be recommended universally. However, less than a third stated that they would find it difficult to discuss the necessity of varicella vaccination with parents. In line with this finding, $79 \%$ of pediatricians and $68 \%$ of GPs perceived parents' general attitude towards having their children vaccinated as positive or rather positive (additional file 2).

Remarkably, $76 \%$ of pediatricians but only $50 \%$ of GPs $(p<0.05)$ felt they will be able to convince parents of the importance of varicella vaccination (Table 2 ).

\section{Potential determinants of attitude towards universal varicella vaccination}

Current vaccination recommendation behavior for varicella $40 \%$ of pediatricians and $27 \%$ of GPs indicated to be currently recommending varicella vaccination for all infants from the approved age (Table 3). Most physicians (64\%) stated to be following the recommendation of varicella vaccination for risk groups according to the NIP and only 2 physicians responded that they are not recommending varicella vaccination to anybody (Table 3). A Mann-Whitney test indicated that the doctors who now recommend varicella vaccination for all infants showed a higher level of intended behavior to recommend UVV compared to those who recommend it only for risk groups (Mean Rank of $89.7 \%$ vs. $66.3 \%$; $p<0.001$ ).

When vaccinating young children against varicella, 76 (51\%) of respondents administer the MMRV combination vaccine for the first dose $(52(58 \%)$ of pediatricians, $24(40 \%)$ of GPs) and $63(42 \%)$ stated that they sometimes or always use separate varicella vaccination (with or without MMR in co-administration in the same visit) for the first dose $(27(30 \%)$ of pediatricians, $36(60 \%)$ of GPs). 11 (12\%) Pediatricians reported to use both MMRV combination vaccine as well as separate varicella vaccination (with or without MMR in co-administration in the same visit) for the first dose.

For the second dose, 78 (52\%) respondents use MMRV (54 (60\%) of pediatricians, 24 (40\%) of GPs) and $52(35 \%)$ of physicians (24 (27\%) of pediatricians, 28 (47\%) of GPs) indicated that they sometimes or always administer the varicella vaccine separately. 11
(12\%) Pediatricians reported to use both MMRV combination vaccine as well as separate varicella vaccination (with or without MMR in co-administration in the same visit) for the second dose and 9 physicians (6\%) stated to not give a second dose (1 pediatrician, $8(13 \%)$ GPs).

\section{Knowledge about varicella}

Based on the knowledge score, 132 (88\%) physicians had a 'moderate' or 'good knowledge' about varicella in general (Table 4). The relationship between varicella and herpes zoster was known to most respondents.

Of the participating physicians, $51 \%$ believed that $75 \%$ of children in Switzerland have had varicella before the age of 11 years and thus underestimated the actual proportion, which is $95 \%$.

Also, the hospitalization rate in children under 16 years due to varicella was underestimated with $61 \%$ of physicians assuming 0.1 or 1 per $10^{\prime} 000$ cases, while the actual rate is 10 per $10^{\prime} 000$ cases.

A Mann-Whitney test indicated that based on the knowledge score pediatricians showed a higher level of knowledge compared to GPs (mean of 3.98 vs. 3.00 on a scale from 0 to $6, p<0.001$ ).

\section{Beliefs about varicella and varicella vaccination}

When asked to rank the importance of vaccination for children for several diseases including tetanus, poliomyelitis, pertussis, measles, mumps, rubella, invasive pneumococcal disease, invasive meningococcal disease, Haemophilus influenzae type b infections (Hib), diphtheria, human papillomavirus (HPV), hepatitis B, tickborne encephalitis (TBE), influenza, rotavirus and varicella, physicians considered varicella vaccination to be among the three least important vaccinations (after rotavirus and influenza). Nevertheless, about half of the participating physicians perceived it to be important or very important to vaccinate children against varicella. Pediatricians attributed a higher importance to varicella vaccination compared to GPs (Table 5).

Although most physicians felt that varicella generally has a mild disease course in healthy children, most respondents acknowledged that it can cause serious complications. Accordingly, there was agreement that varicella is a disease serious enough to vaccinate against (pediatricians: mean score of 3.53 and $67 \%$ either

Table 3 Current recommendation behavior for varicella vaccination

\begin{tabular}{|c|c|c|c|c|c|c|}
\hline \multirow[b]{2}{*}{ Recommendation categories } & \multicolumn{2}{|c|}{ Pediatricians $(\mathrm{N}=90)$} & \multicolumn{2}{|c|}{ GPs $(N=60)$} & \multicolumn{2}{|c|}{ Total $(\mathrm{N}=150)$} \\
\hline & $\bar{N}$ & $\%$ & $\mathrm{~N}$ & $\%$ & $\mathrm{~N}$ & $\%$ \\
\hline For all infants from the approved age & 36 & $40.0 \%$ & 16 & $26.7 \%$ & 52 & $34.7 \%$ \\
\hline Only for risk groups according to the National Immunization Plan (NIP) & 53 & $58.9 \%$ & 43 & $71.7 \%$ & 96 & $64.0 \%$ \\
\hline Not for anybody & 1 & $1.1 \%$ & 1 & $1.7 \%$ & 2 & $1.3 \%$ \\
\hline
\end{tabular}


Table 4 Knowledge of physicians about varicella zoster virus (VZV)

\begin{tabular}{|c|c|c|c|c|c|c|c|}
\hline \multirow[b]{2}{*}{ Questionnaire Item } & \multicolumn{2}{|c|}{ Pediatricians $(\mathrm{N}=90)$} & \multicolumn{2}{|c|}{ GPs $(N=60)$} & \multicolumn{2}{|c|}{ Total $(\mathrm{N}=150)$} & \multirow[b]{2}{*}{$p$-value* } \\
\hline & $\mathbf{N}$ & $\begin{array}{l}\% \\
{[95 \% \mathrm{Cl}]}\end{array}$ & $\mathbf{N}$ & $\%[95 \% \mathrm{Cl}]$ & $\mathbf{N}$ & $\%$ & \\
\hline \multicolumn{8}{|l|}{ In general, you will get varicella only once in your lifetime } \\
\hline Right (correct answer) & 84 & $93.3 \%[88.2-98.5]$ & 46 & $76.7 \%[65.9-87.4]$ & 130 & $86.7 \%$ & 0.003 \\
\hline Wrong & 5 & $5.6 \%[0.8-10.3]$ & 14 & $23.3 \%[12.6-34.0]$ & 19 & $12.7 \%$ & \\
\hline Don't know & 1 & $1.1 \%$ & 0 & 0.0 & 1 & $0.7 \%$ & \\
\hline \multicolumn{8}{|c|}{ The main transmission path of varicella is a contact with fresh varicella blisters } \\
\hline Right (correct answer) & 49 & $54.4 \%[44.2-64.7]$ & 39 & $65.0 \%[52.9-77.1]$ & 88 & $58.7 \%$ & 0.135 \\
\hline Wrong & 41 & $45.6 \%[35.3-55.9]$ & 20 & $33.3 \%[21.4-45.3]$ & 61 & $40.7 \%$ & \\
\hline Don't know & 0 & 0.0 & 1 & $1.7 \%$ & 1 & $0.7 \%$ & \\
\hline \multicolumn{8}{|c|}{ Some potential complications of varicella require the use of antibiotics } \\
\hline Right (correct answer) & 80 & $88.9 \%[82.4-95.4]$ & 41 & $68.3 \%[56.6-80.1]$ & 121 & $80.7 \%$ & 0.002 \\
\hline Wrong & 8 & $8.9 \%[3.0-14.8]$ & 13 & $21.7 \%[11.2-32.1]$ & 21 & $14.0 \%$ & \\
\hline Don't know & 2 & $2.2 \%$ & 6 & $10.0 \%$ & 8 & $5.3 \%$ & \\
\hline \multicolumn{8}{|l|}{ You can only get herpes zoster if you had a varicella infection } \\
\hline Right (correct answer) & 72 & $80.0 \%[71.7-88.3]$ & 36 & $60.0 \%[47.6-72.4]$ & 108 & $72.0 \%$ & 0.008 \\
\hline Wrong & 16 & $17.8 \%[9.9-25.7]$ & 20 & $33.3 \%[21.4-45.3]$ & 36 & $24.0 \%$ & \\
\hline Don't know & 2 & $2.2 \%$ & 4 & $6.7 \%$ & 6 & $4.0 \%$ & \\
\hline \multicolumn{8}{|c|}{ Currently, what is the hospitalization rate due to varicella in children up to the age of 16 years in Switzerland? } \\
\hline 0.1 per $10^{\prime} 000$ cases & 12 & $13.3 \%[6.3-20.4]$ & 11 & $18.3 \%[8.5-28.1]$ & 23 & $15.3 \%$ & \\
\hline 1 per $10^{\prime} 000$ cases & 35 & $38.9 \%[28.8-48.9]$ & 34 & $56.7 \%[44.1-69.2]$ & 69 & $46.0 \%$ & \\
\hline 10 per $10^{\prime} 000$ cases (correct answer) & 36 & $40.0 \%[29.9-50.1]$ & 14 & $23.3 \%[12.6-34.0]$ & 50 & $33.3 \%$ & 0.034 \\
\hline 100 per $10^{\prime} 000$ cases & 7 & $7.8 \%[2.2-13.3]$ & 1 & $1.7 \%[-1.6-4.9]$ & 8 & $5.3 \%$ & \\
\hline \multicolumn{8}{|c|}{ Currently, what percentage of children in Switzerland experiences varicella before the age of 11 years? } \\
\hline $50 \%$ & 7 & $7.8 \%[2.2-13.3]$ & 7 & $11.7 \%[3.5-19.8]$ & 14 & $9.3 \%$ & \\
\hline $75 \%$ & 46 & $51.1 \%[40.8-61.4]$ & 31 & $51.7 \%[39.0-64.3]$ & 77 & $51.3 \%$ & \\
\hline 95\% (correct answer) & 37 & $41.1 \%[30.6-51.3]$ & 22 & $36.7 \%[24.5-48.9]$ & 59 & $39.3 \%$ & 0.585 \\
\hline varicella knowledge score (max 6 points) - rescaled ${ }^{* *}$ & & & & & & & 0.001 \\
\hline 0-2 - Limited knowledge & 4 & $4.4 \%$ & 14 & $23.3 \%$ & 18 & $12.0 \%$ & \\
\hline 3-4 - Moderate knowledge & 59 & $65.6 \%$ & 38 & $63.3 \%$ & 97 & $64.7 \%$ & \\
\hline 5-6 - Good knowledge & 27 & $30.0 \%$ & 8 & $13.3 \%$ & 35 & $23.3 \%$ & \\
\hline
\end{tabular}

*Pearson's $x^{2}$ or Fisher's exact test; $p$-values in bold indicate results that are considered statistically significant after correction for multiple testing by the Benjamini-Hochberg method at a false discovery rate of 0.05

**varicella knowledge score: sum of the first 6 items above where each correct answer was awarded with 1 point, a wrong or missing answer with 0 points

agreeing or agreeing strongly, GPs: mean score of 3.82 and $55 \%$ agreeing or agreeing strongly). Only a minority believed that children should experience varicella to develop specific natural immunity (Fig. 1).

\section{Logistic regression analysis}

Four determinants were statistically significantly associated with a high intention to advise parents to vaccinate their children against varicella if universal varicella vaccination was recommended by the Swiss NITAG in the multivariable logistic regression analysis (Table 6).

First, physicians who are neutral or who agreed with the statement "Varicella is a disease one should have experienced as a child" had a lower probability of intending to recommend UVV in case of a NITAG recommendation in comparison to physicians who disagreed $(\mathrm{OR}=0.067$ and 0.258 , respectively). Second, respondents supporting the statement "I think that varicella is a disease serious enough to vaccinate against" had a higher intention to follow a potential UVV recommendation than respondents who disagreed $(\mathrm{OR}=$ 5.644).

Furthermore, the analysis revealed that the medical specialty as well as fewer years in practice were associated with a positive attitude towards recommending UVV in a statistically significant way: Being a pediatrician increased 
Table 5 Perceived importance of specific vaccinations for children and adolescents as important or very important

\begin{tabular}{|c|c|c|c|c|c|c|c|c|c|}
\hline \multirow[b]{2}{*}{ Questionnaire Item (sorted on Total) } & \multicolumn{3}{|c|}{ Pediatricians ( $\mathrm{N}=90$ ) } & \multicolumn{3}{|c|}{ GPs $(N=60)$} & \multicolumn{3}{|c|}{ Total $(\mathrm{N}=150)$} \\
\hline & $\mathrm{N}$ & $\%$ & Mean score & $\mathrm{N}$ & $\%$ & Mean score & $\mathrm{N}$ & $\%$ & Mean score \\
\hline & \multicolumn{3}{|c|}{$\begin{array}{l}\text { rating } 5 \text { or } 4 \\
\text { (very) important }\end{array}$} & \multicolumn{3}{|c|}{$\begin{array}{l}\text { rating } 5 \text { or } 4 \\
\text { (very) important }\end{array}$} & \multicolumn{3}{|c|}{$\begin{array}{l}\text { rating } 5 \text { or } 4 \\
\text { (very) important }\end{array}$} \\
\hline Measles & 90 & $100.0 \%$ & 4.98 & 59 & $98.3 \%$ & 4.88 & 149 & $99.3 \%$ & 4.94 \\
\hline Tetanus & 88 & $97.8 \%$ & 4.96 & 60 & $100.0 \%$ & 4.98 & 148 & $98.7 \%$ & 4.97 \\
\hline Poliomyelitis & 88 & $97.8 \%$ & 4.81 & 58 & $96.7 \%$ & 4.8 & 146 & $97.3 \%$ & 4.81 \\
\hline Haemophilus influenzae type b infections & 90 & $100.0 \%$ & 4.96 & 56 & $93.3 \%$ & 4.63 & 146 & $97.3 \%$ & 4.83 \\
\hline Whooping cough (Pertussis) & 89 & $98.9 \%$ & 4.92 & 56 & $93.3 \%$ & 4.77 & 145 & $96.7 \%$ & 4.86 \\
\hline Rubella & 86 & $95.6 \%$ & 4.87 & 58 & $96.7 \%$ & 4.82 & 144 & $96.0 \%$ & 4.85 \\
\hline Mumps & 85 & $94.4 \%$ & 4.7 & 56 & $93.3 \%$ & 4.73 & 141 & $94.0 \%$ & 4.71 \\
\hline Diphtheria & 84 & $93.3 \%$ & 4.71 & 57 & $95.0 \%$ & 4.7 & 141 & $94.0 \%$ & 4.71 \\
\hline Invasive Pneumococcal infections & 89 & $98.9 \%$ & 4.88 & 52 & $86.7 \%$ & 4.33 & 141 & $94.0 \%$ & 4.66 \\
\hline Human papillomavirus & 85 & $94.4 \%$ & 4.59 & 52 & $86.7 \%$ & 4.25 & 137 & $91.3 \%$ & 4.45 \\
\hline Invasive Meningococcal infections & 85 & $94.4 \%$ & 4.73 & 50 & $83.3 \%$ & 4.2 & 135 & $90.0 \%$ & 4.52 \\
\hline Hepatitis B & 79 & $87.8 \%$ & 4.58 & 47 & $78.3 \%$ & 4.23 & 126 & $84.0 \%$ & 4.44 \\
\hline Tick-borne encephalitis & 70 & $77.8 \%$ & 4.19 & 45 & $75.0 \%$ & 4.05 & 115 & $76.7 \%$ & 4.13 \\
\hline Chickenpox (Varicella) & 51 & $56.7 \%$ & 3.61 & 28 & $46.7 \%$ & 3.38 & 79 & $52.7 \%$ & 3.52 \\
\hline Influenza & 30 & $33.3 \%$ & 2.93 & 19 & $31.7 \%$ & 2.95 & 49 & $32.7 \%$ & 2.94 \\
\hline Rotavirus & 19 & $21.1 \%$ & 2.58 & 11 & $18.3 \%$ & 2.58 & 30 & $20.0 \%$ & 2.58 \\
\hline
\end{tabular}

I believe that varicella is a burden to working parents and causes productivity loss *

One should not keep children with varicella away from school or childcare

I think that varicella is a disease serious enough to vaccinate against

I am worried about potential side effects of the varicella vaccination *

Varicella is a disease one should have experienced as a child (in order to build up immunity)

\section{Varicella can cause serious complications *}

Varicella generally has a mild disease course in healthy children *

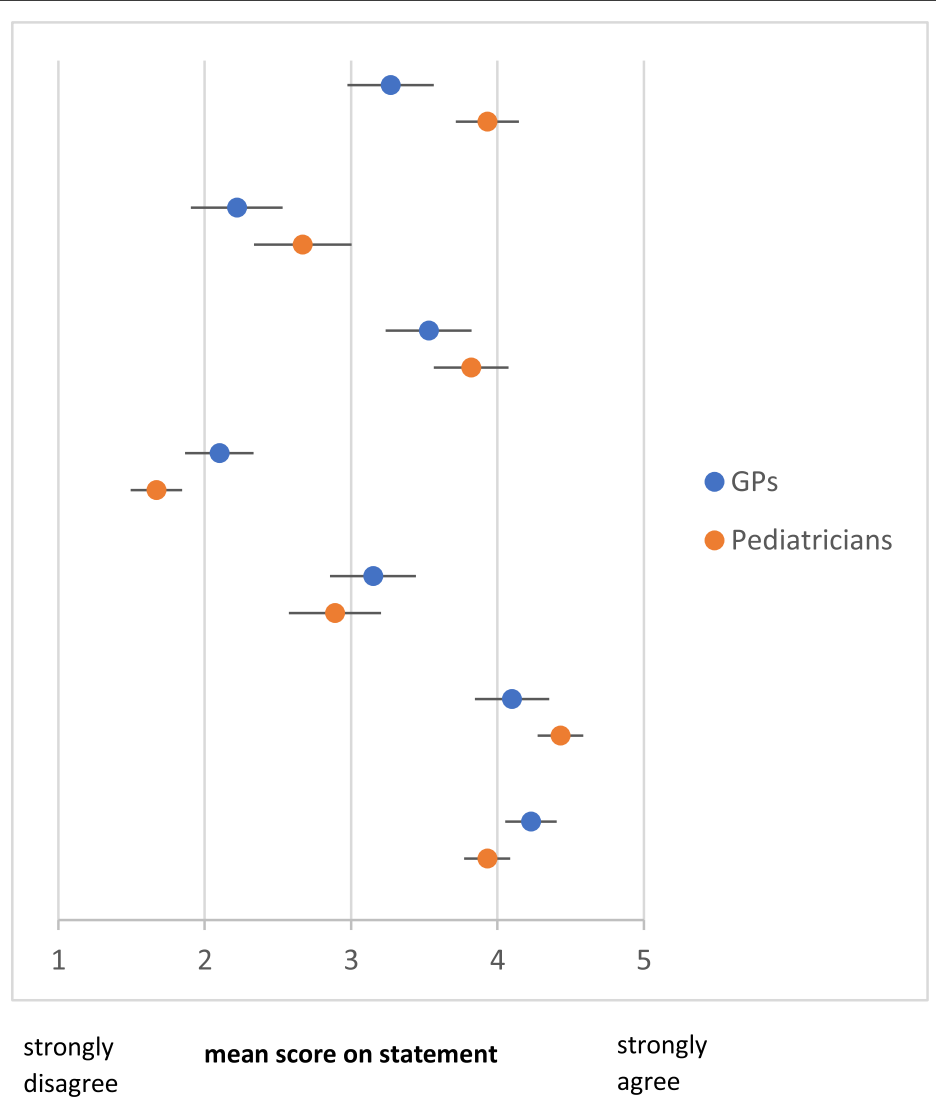

* significant difference between GPs and pediatricians based on Mann-Whitney $U$ testing.

Fig. 1 Mean score on statements regarding the beliefs about the disease varicella and varicella vaccination 
Table 6 Determinants for a high intention to advise parents to vaccinate their children against varicella if universal varicella vaccination was recommended by the Swiss NITAG from univariable and multivariable logistic regression analysis

\begin{tabular}{|c|c|c|c|c|c|c|c|c|c|}
\hline \multirow[b]{3}{*}{ Significant determinants } & \multirow[b]{3}{*}{$N^{b}$} & \multicolumn{8}{|c|}{ Physicians (Pediatricians and GPs combined) } \\
\hline & & \multirow[b]{2}{*}{$B^{c}$} & \multirow[b]{2}{*}{ S.E. $^{d}$} & \multirow[b]{2}{*}{ Wald $^{e}$} & \multirow[b]{2}{*}{$d f^{f}$} & \multirow[b]{2}{*}{ Sig. ${ }^{99}$} & \multirow[b]{2}{*}{$\operatorname{Exp}(B)=O R$} & \multicolumn{2}{|c|}{ 95\% C.I.for OR ${ }^{h}$} \\
\hline & & & & & & & & Lower & Upper \\
\hline \multicolumn{10}{|l|}{ Specialty } \\
\hline Pediatrician & 90 & 1.129 & 0.455 & 6.151 & 1 & 0.013 & 3.091 & 1.267 & 7.542 \\
\hline GP & 60 & Reference & & & & & & & \\
\hline \multicolumn{10}{|l|}{ Beliefs about varicella and varicella vaccination } \\
\hline $\begin{array}{l}\text { Varicella is a disease one should have experienced as a child } \\
\text { (in order to develop immunity) }\end{array}$ & & & & 17.038 & 2 & 0.000 & & & \\
\hline No agreement & 54 & Reference & & & & & & & \\
\hline Neutral & 31 & -2.707 & 0.656 & 17.038 & 1 & 0.000 & 0.067 & 0.018 & 0.241 \\
\hline Agreement & 65 & -1.356 & 0.566 & 5.737 & 1 & 0.017 & 0.258 & 0.085 & 0.782 \\
\hline I think that varicella is a disease serious enough to vaccinate against & & & & 21.432 & 2 & 0.000 & & & \\
\hline No agreement & 31 & Reference & & & & & & & \\
\hline Neutral & 26 & -1.097 & 0.701 & 2.447 & 1 & 0.118 & 0.334 & 0.084 & 1.320 \\
\hline Agreement & 93 & 1.731 & 0.538 & 10.366 & 1 & 0.001 & 5.644 & 1.968 & 16.185 \\
\hline Years in practice & & -0.097 & 0.032 & 9.295 & 1 & 0.002 & 0.908 & 0.853 & 0.966 \\
\hline Constant & & 1.714 & 0.792 & 4.691 & 1 & 0.030 & 5.554 & & \\
\hline
\end{tabular}

a. Variable(s) entered: q13sc_3. Varicella is a disease one should have experienced as a child (in order to build up immunity), q13sc_5. I think that varicella is a disease serious enough to vaccinate against, s2. Specialty, s4. Years in practice

${ }^{\mathrm{b}} \mathrm{N}$ - base for each variable

${ }^{C} B$ - unstandardized regression weight

${ }^{\mathrm{d} S . E .-}$ standard deviation

eWald -test statistic for the individual predictor variable to determine the $p$ value

fdf - degrees of freedom

${ }^{9}$ Sig. - p-value

${ }^{\mathrm{h} C . I .}$ - lower confidence limits (Lower) and the upper confidence limits (Upper)

the probability of having a positive attitude towards a UVV recommendation $(\mathrm{OR}=3.091)$. For physicians with more years of experience - usually older physicians - the probability of having a positive attitude toward a UVV recommendation was lower $(\mathrm{OR}=0.908)$.

While the knowledge score was not a significant determinant in the multivariable logistic regression analysis, a Mann-Whitney test indicated that respondents with a positive attitude towards UVV recommendation showed a higher level of knowledge compared to respondents with a negative attitude $(p<0.032)$.

There was no association between the attitude towards UVV and correct assessment of the hospitalization rate $(p$-value $=0.458)$.

\section{Discussion}

Health care professionals are one of the strongest influencers in vaccination decisions $[16,17]$ and therefore critically influence whether a recommended vaccination reaches high coverage in the population.

In the event the Swiss NITAG would recommend UVV, most participating physicians state that they would advise parents to have their children vaccinated. This expression of compliance was $92 \%$ among pediatricians and $77 \%$ among GPs. As pediatricians in Switzerland are the first-line providers of primary care in the early years of life [18], the finding that more than $90 \%$ of pediatricians in our study showed a high intention to recommend UVV in case of a NITAG recommendation indicates that it should be feasible to achieve high vaccination coverage rates.

The high acceptance of an UVV recommendation in our study is supported by the finding that already more than a third of respondents - predominantly pediatricians - currently recommend varicella vaccination for all infants. It can be speculated that this recommendation behavior is influenced by the experience of nearby countries with universal varicella vaccination programs in place, such as Germany, Italy and Spain $[7,9,10]$.

It is also reassuring that most participating physicians indicated that they have strong arguments to educate parents on the importance of vaccination against varicella.

In line with this finding, about three quarters of the participating physicians perceived parents' attitude towards having their children vaccinated as rather positive.

Nevertheless, further information and education of physicians on varicella should be considered to 
accompany the potential introduction of UVV, especially among the GP population who, according to the results of this study, seem to have a lower awareness of the burden of varicella.

Other recent studies investigated the attitudes to vaccinate against varicella among health care professionals and/or the public at a time when universal varicella vaccination was not recommended. A study previously conducted in the Netherlands showed that health care professionals and parents had a negative attitude or low intention to vaccinate universally against varicella, as a result of the perceived low severity of the disease. Accordingly, there was also very low demand for varicella vaccines in the private market with only $\sim 165$ varicella vaccines for children below 5 years delivered by Dutch community pharmacies in 2014 [14]. In contrast, a small qualitative survey study among 20 caregivers and providers in New Zealand revealed positive support towards universal varicella vaccination and a high intention to vaccinate if available as a routine vaccine [19]. The results of our survey study are thus more comparable to those observed in New Zealand than in the Netherlands.

Other survey studies have focused on parents, rather than on providers. One year after the introduction of a UVV program in Naples, Italy, a survey among 675 parents showed that less than $27 \%$ of parents knew that varicella vaccination was available and that the perceived utility of varicella vaccination was low. Importantly, the positive attitude towards the utility was however higher in those parents who had received information from a health care provider [20]. A survey among visitors of a German internet vaccine forum for lay persons conducted a few months before UVV was introduced in Germany revealed modest acceptance of varicella immunization [16]. Despite this early indication of low initial acceptance among parents, it is noteworthy that varicella vaccination coverage with 1 dose at the age of 24 months reached $>80 \%$ within 4 years after introduction of universal varicella vaccination in Germany [21].

This study has some limitations. The study sample was not fully representative of the Swiss population of pediatricians and the GPs who treat pediatric patients. Physicians from the Italian-speaking part of Switzerland, who make up $4.35 \%$ of all GPs practicing and $4.25 \%$ of all pediatricians practicing in Switzerland [22] were not included. Also, there is potential for selection bias as physicians who were willing to participate in the study might have had more favorable attitudes towards vaccination than the average Swiss pediatrician or GP. Furthermore, the outcome of this study is based on physicians' perceptions and feedback (i.e. stated preferences) and not on a systematic analysis of patient record forms or chart review. Sampling errors could have affected the precision and interpretation of the results. The study is only a cross-sectional analysis at a specific point in time and does not allow an interpretation of developments or trends over time. The regression model analysis did not take into account all relevant confounders leading to unmeasured confounding bias. Finally, the questionnaire used for the survey study is not a standardized, validated questionnaire. Therefore, outcomes of this study are not comparable with those from other countries or studied samples.

Still, this is the first survey study among pediatricians and GPs in Switzerland specifically addressing varicella vaccination. Many aspects need to be taken into consideration in a national decision-making process about UVV, as has been outlined by a report of the European Centre for Disease Prevention and Control [23]. The findings of this survey study may assist the Swiss NITAG in its evaluations of the feasibility of UVV introduction in the national immunization schedule.

\section{Conclusions}

The results of this survey show that most participating pediatricians and GPs indicated a favorable attitude towards childhood vaccination against varicella in the setting of a Swiss NITAG recommendation for UVV. This data also shows the importance of NITAG recommendations in influencing vaccine education and supporting achievement of high coverage of varicella vaccination.

\section{Supplementary Information}

The online version contains supplementary material available at https://doi. org/10.1186/s12879-020-05586-3.

Additional file 1. Study questionnaire.

Additional file 2. Perceived general attitude of parents towards having their children vaccinated according to NITAG recommendations.

\section{Abbreviations}

UW: universal varicella vaccination; NITAG: National Immunization Technical Advisory Group; GPs: general practitioners; VZV: varicella zoster virus; NIP: National Immunization Plan; MMRV: measles, mumps, rubella, varicella combination vaccine; MMR: measles, mumps, rubella combination vaccine

\section{Acknowledgements}

We would like to thank all physicians for participating in our survey study.

\begin{abstract}
Authors' contributions
FL was involved in designing the study, interpreting the data and in writing the manuscript. OW was involved in designing the study, collecting and analyzing the data and in writing the manuscript. KS was involved in designing the study, collecting and analyzing the data and in writing the manuscript. UH was involved in designing the study, interpreting the data and in writing the manuscript. PG was involved in designing the study, interpreting the data and in writing the manuscript. All authors have read and approved the manuscript.
\end{abstract}

\section{Funding}

This study was funded by MSD Merck Sharp \& Dohme AG Switzerland. FL and PG are former or current employees of MSD Merck Sharp \& Dohme AG Switzerland and have been involved in the design of the study and the analysis and interpretation of data as well as in writing the manuscript. 


\section{Availability of data and materials}

The datasets used and/or analysed during the current study are available from the corresponding author on reasonable request.

\section{Ethics approval and consent to participate}

Ethical review and approval were not required in accordance with the local legislation (Swiss federal law on research on humans, https:/www.admin.ch/ opc/de/official-compilation/2013/3215.pdf). Participating physicians gave their written informed consent before filling out the online questionnaire (see additional file 1).

\section{Consent for publication}

Not applicable.

\section{Competing interests}

FL and PG are former or current employees of MSD Merck Sharp \& Dohme AG Switzerland, a manufacturer of varicella vaccines. The other authors declare that they have no competing interests and no honorarium was paid to $\mathrm{UH}$ or his institution.

\section{Author details}

${ }^{1}$ MSD Merck Sharp \& Dohme AG, Lucerne, Switzerland. ${ }^{2}$ Current affiliation: Bavarian Nordic AG, Zug, Switzerland. ${ }^{3}$ IPSOS, Basel, Switzerland. ${ }^{4}$ Department of Pediatric Infectious Diseases and Vaccinology, University of Basel Children's Hospital, Basel, Switzerland.

Received: 7 May 2020 Accepted: 4 November 2020

Published online: 06 January 2021

\section{References}

1. Arvin AM. Varicella-zoster virus. Clin Microbiol Rev. 1996;9(3):361-81.

2. Heininger U, Seward JF. Varicella. Lancet. 2006;368(9544):1365-76.

3. Bonhoeffer J, Baer $\mathrm{G}$, et al. Prospective surveillance of hospitalisations associated with varicella-zoster virus infections in children and adolescents. Eur J Pediatr. 2005;164(6):366-70.

4. Bundesamt für Gesundheit, Schweizerischer Impfplan 2020.

5. Bollaerts $\mathrm{K}$, Riera-Montes $\mathrm{M}$, et al. A systematic review of varicella seroprevalence in European countries before universal childhood immunization: deriving incidence from seroprevalence data. Epidemiol Infect. 2017;145(13):2666-77.

6. Lopez AS, Zhang J, et al. Epidemiology of varicella during the 2-dose varicella vaccination program - United States, 2005-2014. MMWR Morb Mortal Wkly Rep. 2016 Sep 2;65(34):902-5.

7. Siedler A, Dettmann M. Hospitalization with varicella and shingles before and after introduction of childhood varicella vaccination in Germany. Hum Vaccines Immunother. 2014;10(12):3594-600.

8. Spoulou V, Alain $\mathrm{S}$, et al. Implementing universal varicella vaccination in Europe. Pediatr Infect Dis J. 2019:38:181-8.

9. Bechini A, Boccalini S, et al. Impact of universal vaccination against varicella in Italy. Hum Vaccin Immunother. 2015;11(1):63-71.

10. Gil-Prieto $\mathrm{R}$, Walter $\mathrm{S}$, et al. Different vaccination strategies in Spain and its impact on severe varicella and zoster. Vaccine. 2014 Jan;32(2):277-83.

11. Varela FH, Pinto LA, et al. Global impact of varicella vaccination programs. Hum Vaccin Immunother. 2019;15(3):645-57.

12. Halloran ME, Cochi SL, et al. Theoretical epidemiologic and morbidity effects of routine varicella immunization of preschool children in the United States. Am J Epidemiol. 1994;140(2):81-104.

13. Van Hoek AJ, Melegaro A, et al. Modelling the impact of a combined varicella and zoster vaccination programme on the epidemiology of varicella zoster virus in England. Vaccine. 2011 Mar 16;29(13):2411-20.

14. Van Lier A, Tostmann A, et al. Negative attitude and low intention to vaccinate universally against varicella among public health professionals and parents in the Netherlands: two internet surveys. BMC Infect Dis. 2016; 16:127. https://doi.org/10.1186/s12879-016-1442-1.

15. Benjamini $Y$, Hochberg $Y$. Controlling the false discovery rate: a practical and powerful approach to multiple testing. J R Stat Soc B (Methodological). 1995;57(1):289-300.

16. Heininger $U$. An internet-based survey on parental attitudes towards immunization. Vaccine. 2006;24(37-39):6351-5.

17. Paterson $P$, et al. Vaccine hesitancy and healthcare providers. Vaccine. 2016 Dec 20;34(52):6700-6.
18. Jenni OG, Sennhauser FH. Child health Care in Switzerland. Child health Care in Switzerland. J Pediatr. 2016;177S:S203-12.

19. Charania NA, Watson DG, et al. Perceptions of caregivers and providers regarding the potential introduction of the varicella vaccine to the childhood immunization schedule in New Zealand: a qualitative exploratory study. J Paediatr Child Health. 2018;54:28-35.

20. Vezzosi L, Santagati G, et al. Knowledge, attitudes, and behaviors of parents towards varicella and its vaccination. BMC Infect Dis. 2017;17(1):172.

21. Rieck $T$, et al. Vaccination coverage among children in Germany estimated by analysis of health insurance claims data. Hum Vaccin Immunother. 2014; 10(2):476-84.

22. IQVIA Solutions. Healthcare Address-Guide (edition February 2020).

23. European Centre for Disease Prevention and Control. Varicella vaccination in the European Union. Stockholm: ECDC; 2015.

\section{Publisher's Note}

Springer Nature remains neutral with regard to jurisdictional claims in published maps and institutional affiliations.
Ready to submit your research? Choose BMC and benefit from:

- fast, convenient online submission

- thorough peer review by experienced researchers in your field

- rapid publication on acceptance

- support for research data, including large and complex data types

- gold Open Access which fosters wider collaboration and increased citations

- maximum visibility for your research: over $100 \mathrm{M}$ website views per year

At BMC, research is always in progress.

Learn more biomedcentral.com/submissions 